\title{
Theoretical aspects concerning working fluids in hydraulic systems
}

\author{
Irina Tița ${ }^{1, *}$, Irina Mardare ${ }^{1}$ and Dorin Emil Husaru ${ }^{2}$ \\ ${ }^{1}$ Technical University "Gheorghe Asachi” Iași, Department of Fluid Mechanics, Fluid Machinery and \\ Fluid Power Systems, Blvd. D. Mangeron, 59A, 700050, Iasi, România \\ ${ }^{2}$ Technical University "Gheorghe Asachi” Iași, Department of Mechanical Engineering, Mechatronics \\ and Robotics, Blvd. D. Mangeron, 43, 700050, Iasi, România
}

\begin{abstract}
Among the properties of working fluid, viscosity is the most important as it regards especially to pumps. In order to study the behavior of hydrostatic transmission it is important to create a reliable research instrument for dynamic simulation. Our research expertise being in SimHydraulics consequently this instrument is the suitable block diagram. The purpose of this paper is to present the possible ways to customize the properties of the working fluid in the block diagram.
\end{abstract}

\section{Introduction}

In fluid power systems the working fluid has to transmit energy. It must transmit the prime movers energy to the actuator so it can perform work. The fluid must flow easily to reduce power losses and make the circuit respond quickly $[1,2]$.

Among the properties of working fluid, viscosity is the most important as it regards especially to pumps. One can use either dynamic viscosity $\eta\left[\mathrm{N} \cdot \mathrm{s} / \mathrm{m}^{2}, \mathrm{~Pa} \cdot \mathrm{s}\right.$ in SI or Poise in CGS] or kinematic viscosity $v\left[\mathrm{~m}^{2} / \mathrm{s}\right.$ in SI or St in CGS] knowing that dynamic viscosity is the quantitative expression of fluid's resistance to flow, while kinematic viscosity is the ratio of the fluid's viscous force to the inertial force and kinematic viscosity is the ratio of dynamic viscosity to density. In this paper viscosity will be used for kinematic viscosity.

$$
v=\eta / \rho
$$

Most manufacturers specify viscosity limits for their pumps and it is recommended to stay within the suggested limits. Pressure drop in the pump suction line generally is low and if the oil is too thick the pump will be damaged due to cavitation. On the other end, if fluids are too thin, pump bypass wastes energy and generates extra heat.

All other components in the circuit could operate on any viscosity fluid because they only use what is fed to them. However, thicker fluids waste energy because they are hard to move $[3,4]$.

There are two critical aspects regarding working fluid: the resilience of the hydraulic fluid's viscosity across a wide range of operating temperatures and the shear stability of the hydraulic fluid - sufficient to withstand the stress of demanding operating conditions.

\footnotetext{
*Corresponding author: iddtita@yahoo.com
} 
Considering that the main interest in our research laboratory is on hydrostatic transmissions used in wind turbines and the fact that the average range of operating temperature over a year is of $60^{\circ} \mathrm{C}$, viscosity of the working fluid is very important.

In order to study the behavior of hydrostatic transmission it is important to create a reliable research instrument for dynamic simulation. Our research expertise being in SimHydraulics consequently this instrument is the suitable block diagram. The purpose of this paper is to present the possible ways to customize the properties of the working fluid in the block diagram.

\section{Working fluid properties}

Viscosity is the most important property of the working fluid in hydrostatic transmissions. Viscosity of every hydraulic fluid depends on its operating temperature Fig. 1 [5].

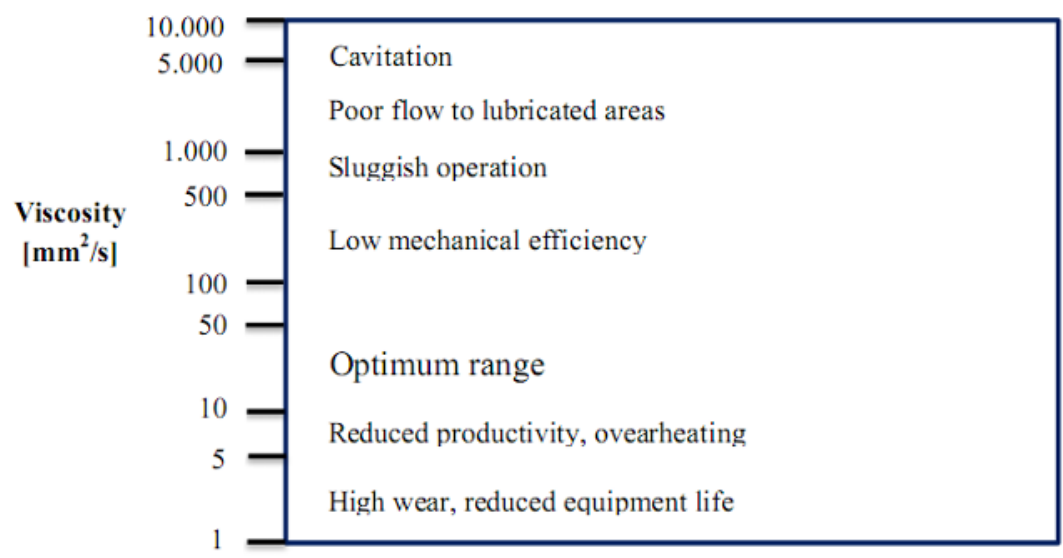

Fig. 1. Kinematic viscosity domains.

The ideal viscosity range for a fluid - and thus its highest efficiency - is usually between 10 and $100 \mathrm{~mm}^{2} / \mathrm{s}$, depending on the application. If a hydraulic fluid is too thin this leads to increased wear, lower power transmission, lower volumetric efficiency and overheating. A fluid of too high a viscosity leads to a loss of power, decreased mechanical efficiency, and in the worst cases, cavitation and mechanical failure.

The operable range of temperatures in which a fluid is effective is called its "temperature operating window - TOW" [4] (Fig. 2).

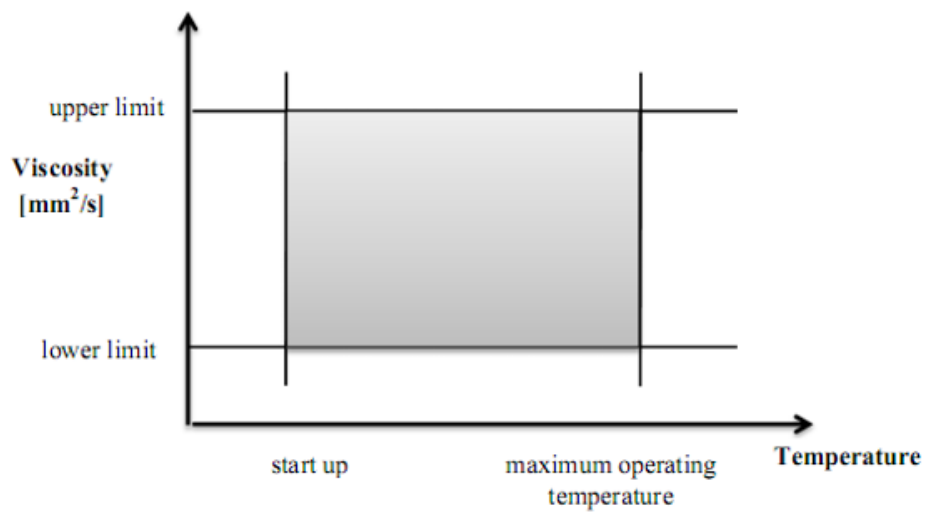

Fig. 2. Temperature operating window - TOW. 
The position and the width of the window depend largely on the characteristics of the pump and the hydraulic fluid itself. The operating temperature requirements are defined by the application. Within these limits, from start up to emergency situations, the fluid has to protect the hydraulic equipment. A measure of viscosity change from one temperature to another is viscosity index - VI. Most industrial hydraulic oils run in the 90 to 105 -VI range and are satisfactory for most applications. Viscosity modifiers enhance the oils ability to remain at a workable viscosity through a broad temperature range [1,4].

Viscosity has to be high enough to protect the equipment and to guarantee pump efficiency. On its way from the tank to the pump, the fluid has to pass several hydraulic resistances. Friction within the fluid itself and friction on the walls and compression in the pump creates heat, heat that reduces the viscosity.

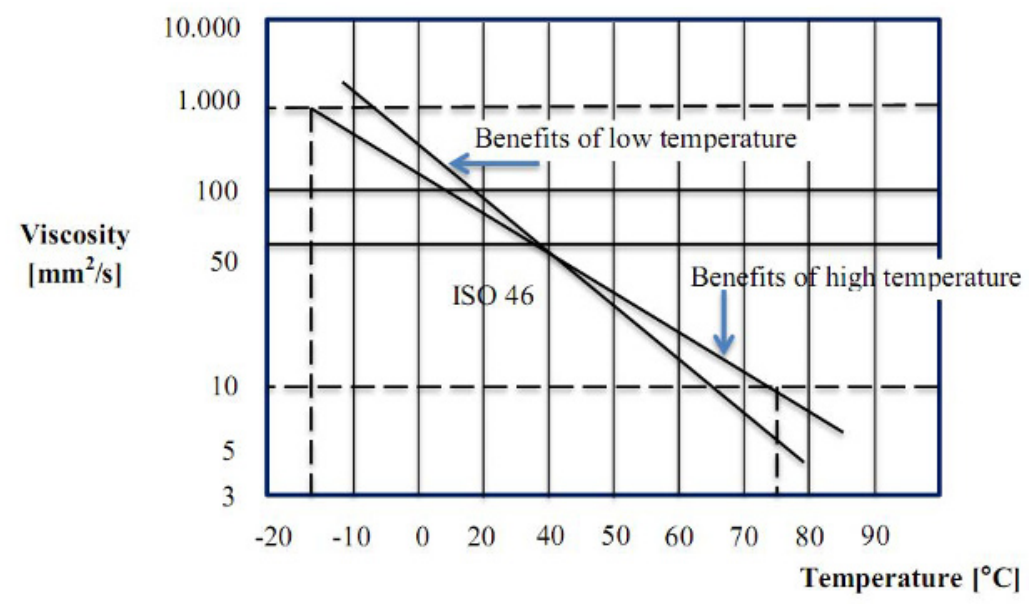

Fig. 3. Case study for two oils meeting ISO 46 Viscosity [5].

The diagram in Fig. 3 shows the viscosity of two fluids across a range of operating temperatures. While both fluids meet pump manufacturer requirements, the fluid with the higher viscosity index (VI) permits a broader Temperature Operating Window (TOW). One may see the comparatively high viscosity of the High VI fluid when reaching high temperature (higher volumetric efficiency) as well as its comparatively lower viscosity at low temperatures (higher mechanical efficiency) [6].

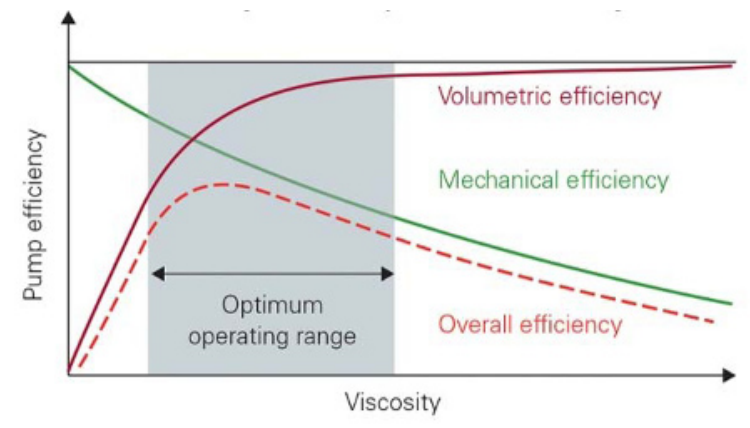

Fig. 4. Pump efficiency according to kinematic viscosity [7].

While the amount of conveyed oil grows with increased viscosity, the mechanical efficiency of the pump is decreasing Fig. 4. The overall efficiency of a pump is the product of both curves. Only with a suitable viscosity for its hydraulic fluid will a pump work 
efficiently. If a hydraulic fluid can be maintained within an efficient viscosity range throughout its entire operating temperature spectrum, the pump will operate more efficiently.

Given that petroleum oil can pollute drinking water, with the agricultural and mining industries being major consumers of hydraulic fluid, bio based hydraulic fluids are used in environmentally sensitive applications when there is the risk of an oil spill. Vegetable oils from Canola used as base stocks for fluids where biodegradability is considered important. [8]. Some of the significant advantages of using biodegradable hydraulic fluids are: adequate viscosity and viscosity index, proper viscosity to minimize internal leakage low temperature fluidity, cleanliness and filterability, corrosion control, shear stability, low volatility etc.

\section{Hydraulic fluid in SimHydraulics}

In order to consider properties of working fluid Matlab / SimHydraulics has two blocs: Custom Hydraulic Fluid -Simscape/Foundation Library/Hydraulic Utilities and Hydraulic Fluid Simscape/SimHydraulics/Utilities [9] (Fig. 5 and Fig.6).

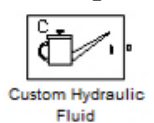

Fig. 5. Custom Hydraulic Fluid Block.

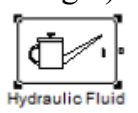

Fig. 6. Hydraulic Fluid Block.

In Custom Hydraulic Fluid block one can specify, according to producer's specifications: fluid density, kinematic viscosity, bulk modulus and relative amount of air trapped, as one can see in Fig. 7.

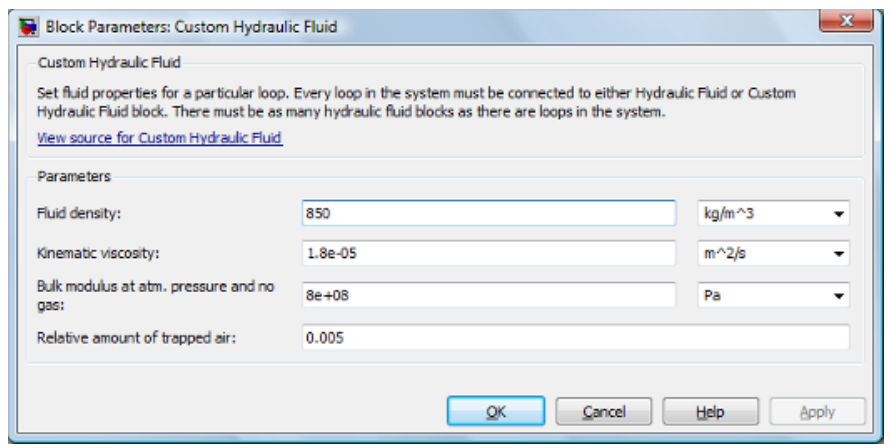

Fig. 7. Bloc parameters for Custom Hydraulic Fluid.

Hydraulic Fluid block offers a drop-down list of some fluids (Fig. 8).

Fluids in the list can be grouped in the following categories: a) Skydrol eco-friendly, fire resistant intended for lubrication components, aircraft use [10]; b) HyJet synthetic oils, fire resistant, stable at temperature variation, intended for aircraft use [11]; c) Fluid MIL oils are military specifications, synthetic hydrocarbon base, fire resistant for aircraft use [12]; d) Oil $10 \mathrm{~W}$ is synthetic engine oil, high VI, for heavy vehicles use; e) Oil SAE is a synthetic motor oil for heavy vehicle use also [11, 13]; f) Transmission fluid ATF (Dexron III) is synthetic, high VI, for cars automatic transmission or any other hydraulic transmission [11, 13]; g) ISO VG oils are industrial mineral oils with good anti-foaming, anti-oxidant and anti-rust characteristics, ISO VG 22 generally used in airlines for air tools, ISO VG 32 ideal for use in high-powered machine tools, ISO VG 46 is normally required for industrial plant working under high-pressure etc. [14]; h) Brake fluids are synthetic oils with additives to improve performances in extreme functioning conditions, for vehicles braking systems [11]; i) Gasoline is a product fuel gas resulting from the liquefaction; $j$ ) Diesel fuel is a hydrocarbon 
mixture useful for Diesel engines; k) Jet Fuel is a hydrocarbon mixture useful for aircraft engines [11]; 1) Water-Glycol 60/40 is mix with frost protection up to a temperature of $51^{\circ} \mathrm{C}$, nontoxic fluid and consequently used for hydrostatic transmission or cooling systems in pharmaceutical or food industry

Selecting working fluid parameters: type, relative amount of trapped air and temperature, corresponding fluid properties: density, viscosity and bulk modulus will be automatically selected from the characteristics.
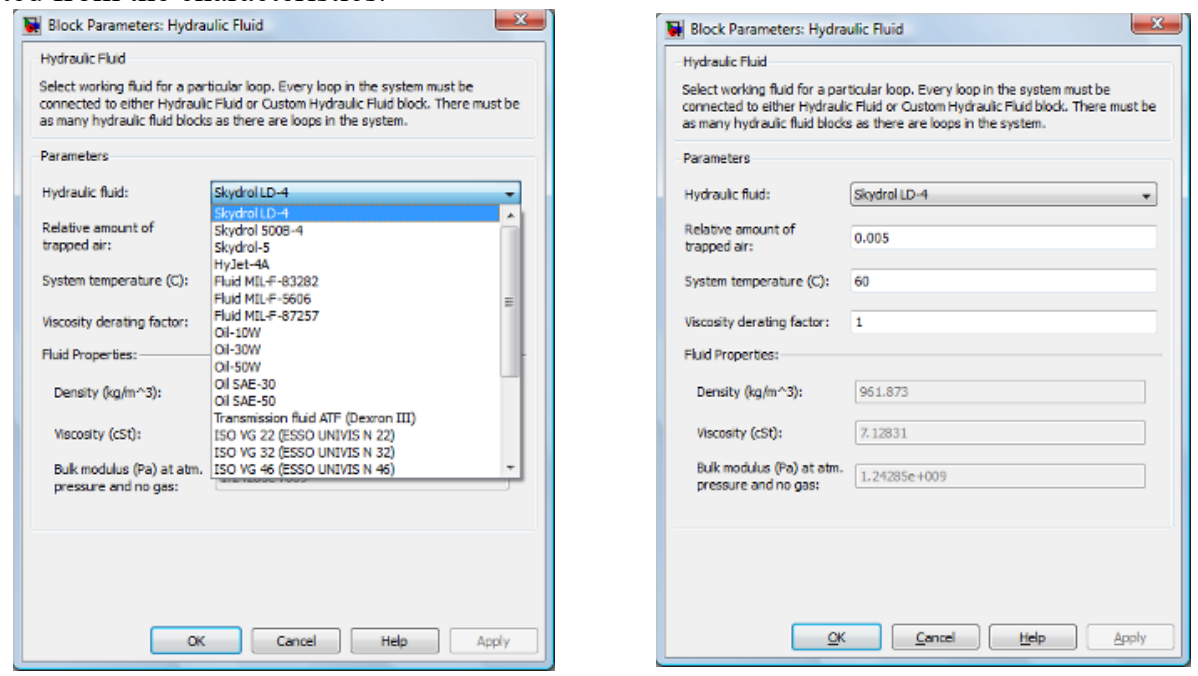

Fig. 8. Bloc Parameters for Hydraulic Fluid.

One can get information on the fluids and their properties considered in the literature used in MATLAB $^{\circledR}$ list of fluids. Information is given as plots for viscosity, density and bulk modulus with temperature.

For researches in our laboratory it has been identified some problems regarding a simulation diagram: how could one consider the influence of the temperature variation; how to consider a variation with temperature for a property (e.g. viscosity) founded to be different from the one considered in MATLAB including vegetable fluids and how to consider the possible change of a property after a number of working hours.

Our laboratory offers technical resources and expertise to determine viscosity curve for a fluid. For example for SAE 10W-60 dynamic viscosity $\eta$ variation obtained is presented in Fig.9 [15].

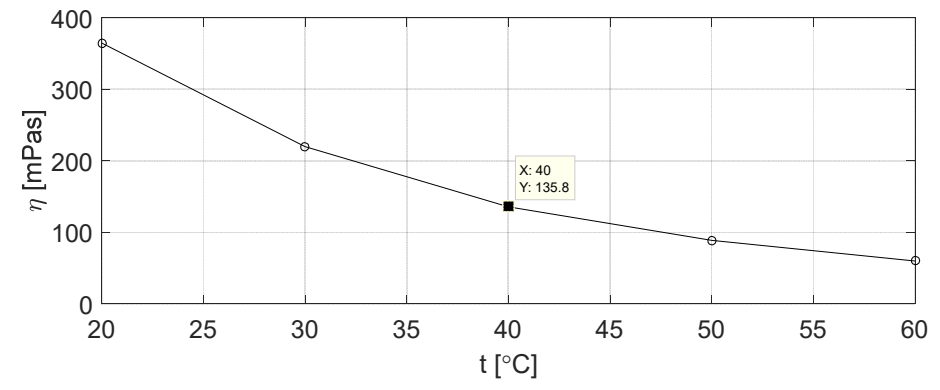

Fig. 9. Approximated dynamic viscosity.

In order to solve the identified problems we intend to evaluate the fluid properties at the beginning and after a measured number of working hours. For the simulation diagram we intend to create a new component which will consider the properties as a Lookup Table 
depending on temperature variation. In the table will be considered the properties of the fluid obtained with RheolabQC.

\section{Conclusions}

If a hydraulic fluid is too thin this leads to increased wear, lower power transmission, lower volumetric efficiency and overheating. A fluid of too high a viscosity leads to a loss of power, decreased mechanical efficiency, and in the worst cases, cavitation and mechanical failure. It is of high importance to choose the working fluid.

In order to study the behavior of hydrostatic transmission it is important to create a reliable SimHydraulics block diagram as a research instrument for dynamic simulation. fluid.

In this paper was revealed the actual SimHydraulics possibilities for using a working

Considering the final purpose of the research which consists in hydrostatic transmissions for wind turbines, the main specific problems regarding the working fluid was identified and also the future researches.

The authors would like to acknowledge the technical resources offered by the Laboratory of Fluid Properties Measurement, from the Department of Fluid Mechanics, Fluid Machinery and Fluid Power Systems, "Gheorghe Asachi" Technical University of Iasi, Romania. The Laboratory of Fluid Properties Measurement has been equipped with technical resources with the financial support of the grant ENERED, POSCCE-A2-O2.2.1-2009-4, ID 911.

\section{References}

1. J. Watton, Springer Verlag, London, (2007).

2. J. Watton, Cambridge University Press, London, (2009).

3. S. Lunt, T. Meindorf, 9 IFK, 3, 11, (2014)

4. Hydraulics \& Pneumatics http://hydraulicspneumatics.com/fluid-powerbasics/hydraulics (accessed 18.02.2017)

5. DynaVis http://formulators.dynavis.com/cms/formulators/en/hydraulic-fluidperformance/viscosity/pages/default.aspx, (accessed 25.02.2017)

6. H. Murenhoff, Proceeding of the 12th International Conference on Tools: ICT-2007, Miskolc, (2007).

7. Machinery Lubrication http://machinerylubrication.com/Read/776/maximumefficiency-hydraulic-fluids (accessed 17.02.2017)

8. D. Placek, (edited by L. Rudnick ed., CRC Press, 2006).

9. MATLAB/Simscape https://uk.mathworks.com/products/simscape.html (accessed 10.02.2017)

10. Skydrol http://www.eastman.com/Brands/EAS/Skydrol/Pages/Home.aspx accessed 22.02.2017

11. Viscopedia www.viscopedia.com (accessed 20.02.2017)

12. QC Lubricants http://qclubricants.com/hydraulic fluid mil.htm

13. Castrol http://www.castrol.com/en us/united-states/other-fluids/automatictransmission-fluid-atf.html (accessed 25.02.2017)

14. Crownoil https://www.crownoil.co.uk/lubricants/all-you-need-to-know-abouthydraulic-oil/ (accessed 22.02.2017)

15. D. Zahariea, D. E. Husaru, IManEE, 6 (2017). 